\title{
How gaming, artificial intelligence and big data is changing education
}

\author{
A scalable solution that makes education accessible to everyone.
}

\begin{tabular}{c}
\hline Teo Peihan Janine \\
Solve Education! \\
Jakarta, Indonesia \& Singapore \\
Janine@solveeducation.org \\
\hline
\end{tabular}

Abstract-With 263 million children and youth out of school, there is a need for a highly scalable way to provide quality education to the underprivileged. Solve Education!(SE!)'s solution is combining an addictive game with the "Learning-by-Doing" Principle. Leveraging artificial intelligence and big data analysis, SE! explores the possibility of combining multi-user online strategy games with casual puzzle games to increase user retention rates, and in the process educating the users effectively over a longer period of time.

Game mechanics are used to increase user retention by boosting motivation, while big data analysis allows SE! to understand the users' in-game behavior and how they learn best. Artificial intelligence helps to deliver the right content to the user at the right time, optimizing the learning process, and enabling in-game adaption to the users' learning needs.

Keywords-Game-based learning; edutainment; AI; analytics; pedagogy; big data

\section{INTRODUCTION}

Research in education games is gaining more traction with the rapid increase of mobile phone penetration, mainly driven by the decrease in mobile phone pricing. Digital games become more widely regarded as high potential educational tools [1]. As a result, some digital games have already been introduced into classrooms, for example Minecraft.

Kirriemuir and McFarlane (2004) explained that digital games employed in education can be broadly divided into two subcategories: 1) mainstream games, i.e. games that are created solely for fun and 2) education games, i.e. games that are designed with explicit education purposes [2].

Social media and messaging apps are still topping the charts in terms of download rates and user retention rates. This is closely followed by games. The most popular games - those that are able to retain the users for the longest period of time tend to fall either under the genre of multi-user online strategy games (for example, Clash of Clans) or casual puzzle games (for example, Candy Crush). It is also interesting to note that no education games are usually (unless you can prove that it has never happened) listed in the charts. [3] While there are quite a number of education games that belong to the casual puzzle game genre, there are few multi-user online strategy education games.

Solve Education! (SE!) explores the possibility of combining multi-user online strategy games with casual puzzle games to increase user retention rates, and as a result potentially becoming able to educate users over a longer period of time. As we are targeting the out-of-school children and the children who do not have access to quality education, our solution is designed to support both online and offline play, as well as run on lower-end Android devices.

There are 263 million children and youth who are out of school globally, from primary to upper secondary levels [4]. SE!'s solution aims to address this challenge at a scalable way.

\section{REFERENCE FRAMEWORKS FOR GAME DESIGN}

There is an increase of emphasis on teaching soft skills such teamwork, critical reasoning, and empathy. Van Eck (2006) provides many examples of multi-user online strategy games being used in the classroom, including Age of Empires (history), The Sims (building complex social relationships) and Sim City (Civil Engineering and Government) [5]. According to Van Eck, it is important for teachers to insert the game experience in a sound overall educational framework, augmenting the game with contextualized instructional activities.

SE! builds around such a sound educational framework, with a platform which allows teachers to insert their own content. This content flows through the game and is delivered to the student, according to their competence level and learning style, steered by artificial intelligence. The Meta game is a city building game, and it incentivizes the users to play the mini games, which are templates where different content can be fed in.

The Meta game is of the multi-user online strategy game genre and is designed to develop soft skills, while the mini games are of the casual puzzle game genre and are designed to educate according to classroom content, and job related skills using simulation.

Games can present users with realistic and compelling challenges, making learning relevant, applied and practiced 
within that context. Roger C. Schank explained that engagement in the job, even if only as a simulation, significantly increases students' knowledge retention [6]. This approach has been used to train highly skilled professionals, for example, fighter pilot training (United States Navy Fighter Weapons School, previously known as Top Gun).

When designing Game Mechanics, the three key attributes below are considered [7]:

- Game Mechanics Types: Progression, Feedback and Behavior

- Boosts (Benefits): Engagement, Loyalty, Time Spent, Influence, Fun, Search Engine Optimization (SEO), User Generated Content (UGC), Virality

- Personality Types: Explorers, Achievers, Socializers, Combaters

\section{A. Progression Game Mechanics}

Progression Game Mechanics appeal most to Achievers, but also to Combaters. Achievers enjoy the feeling of progression, while Combaters enjoy winning and trying to be ahead of other users. Here are some examples of Progression Game Mechanics:

1) Achievements

2) Levels

3) Points

In the SE! app, there are a wide range of achievements for the users to aspire towards, for example, Spelling Bee or Super Builder. With each mission completed in the game, the user will earn points and progress in the Meta game. Each desirable action in the Meta game will increase the level of the user, hence unlocking rare items and other achievements.

\section{B. Feedback Game Mechanics}

Feedback Game Mechanics is most attractive to Achievers, and also Explorers. Here are some examples of Feedback Game Mechanics:

1) Combos

2) Bonuses

3) Countdown

4) Reward Schedules

5) Quests

6) Appointments

7) Cascading Information Theory

8) Loss Aversion

In the SE! app, the meta game offers bonuses that are scheduled to encourage consistent learning on a daily basis. Quests, in form of missions, are incorporated in form of casual games. Loss aversion is incorporated into the game where the users are able to visit each other in the Meta game, and do funny things in their friends' cities, hence encouraging users to $\log$ into check the situation from time to time.

\section{Behavior Game Mechanics}

As Behavior Game Mechanics appeal to all personality types, they are heavily emphasized in the SE! app. Some examples include:

1) Virality

2) Community Collaboration

3) Infinite Gameplay

4) Discovery

5) Blissful Productivity

6) Ownership

7) Status

8) Urgent Optimism

9) Free Lunch

10) Luck

11) Behavioral Momentum

12) Epic Meaning

In the game, there are missions that require multiple users to play as a team, encouraging them to help each other, thus incentivizing community collaboration and enabling virality. There are counters that limit the points you can earn from each mini game in each given time period, putting the user under time pressure and creating a sense of urgent optimism. Discovery is encouraged as the user explores the cities built by the other players.

\section{Motivation AND GAME MEChanics}

There are many studies on how motivation is the key component in learning. According to Williams (2011) [7], the five key ingredients for improving student motivation are: Student; Teacher; Content; Method/Process; Environment.

\section{A. Students}

Considering that our target audience is not attending school education, a replacement to motivate them is required. This is even more important as these youth are often in environments that are not conducive to learning. For example, parents might not see the benefits of education, thus discouraging the children from getting educated). The SE! app uses the same game mechanics that the most popular games deploy to drive high user retention, but instead in order to motivate users to continue their learning process.

\section{B. Teachers}

Teachers remain an essential part of the learning process. For students who have access to teachers, the SE! app will be a supplement to the classroom lessons. SE! will provide the analytics to teachers, enabling them to better understand their students' progress and learning needs.

For users who are out of school or do not have access to teachers, the SE! app uses artificial intelligence to emulate teachers in form of different characters within the game, so as to provide users with the support that they require.

\section{Content}

SE! will provide the platform for different content providers (teachers, educators, subject matter experts) to enter 
and deploy their content. This is to enable users to access a wide range of subjects and learning experiences.

The content flows into the game and is delivered to users in reflection of their competency level and learning requirements.

\section{Method and Process}

SE!'s game combines a multi-user online strategy game with casual puzzle games. The game is in closed beta at the moment, and is called "Dawn of Civilization" (as voted for by our beta users). The Meta game is a multi-user city building strategy game, which drives the users to pay for the mini games. These are designed as casual puzzle games and are where the learning happens. In order to progress in the Meta game, the users have to play and complete the mini games.

The first step is to build basic literacy and numerical reasoning. After the users establish these foundations, most of the other parts of the education will use the Learning-by-Doing Principle [8]. For example, if the user would like to explore and learn to become an accountant, the game will provide a job simulation for the user, i.e., in the game, the user is an accountant and the game will be delivering the required information/lessons, just when the user needs to use them.

\section{E. Environment}

SE!'s game creates an environment in the game that will be the same for all users, hence regardless of the actual environment that the users are in, they can all have the same experience.

The game is also designed to teach soft skills such as teamwork and negotiation skills. For example, there are missions in the game that requires the users to work as a team and help each other.

\section{Big Data Analysis}

There are many articles on how big data is changing the game industry. Unlike other industries, the challenge does not lie in data collection, but in how to analyze and make the best of it [9]. Understanding the players takes the companies to the next level. Big Fish Games - the world's largest producer and distributor of casual games - used big data analytics, and found that more experimental analysis boosts player satisfaction scores [10].

This is the approach that SE! is going to take in the game development process. With the data, we will also be analyzing how users learn best, using applied cognitive science. This means that $\mathrm{A} / \mathrm{B}$ testing will be conducted with our beta users, testing different variables from number of repetitions, reward structure to background music and colors. The testing is done with the objective of discovering the variables that best support learning.

This approach requires the collection and analysis of a large amount of data tracking users while they are interacting with the game. Hence, the first phase of the roll out for the game is to 100 Indonesian youth, and the next phase is to 10,000 youth.

Once this data is collected, big data analysis will be conducted to better understand the users' behavior and to research further on using games as the pedagogical approach. The data will be used to further improve the app.

Artificial intelligence is used to deliver the most appropriate content, through the most effective approach to each individual user. The learning outcomes are measured against the learning objectives, and system uses this feedback to learn about how each individual is interacting with the game, and further personalize the user's learning experience.

\section{CONCLUSION AND FUTURE WORK}

Currently, SE! has just completed the alpha milestone, and has 100 beta users from Jakarta and Bandung, aged between 16-20 years old. The beta version will be released at the end of 2016. The registration for the next phase of roll out is on track to hit 10,000 test users, mostly from Indonesia. There will also be 100 users each from the Philippines, Thailand, Malaysia and Vietnam respectively.

After the successful rollout to this age group, the app will then be opened to younger and older audiences.

\section{ACKNOWLEDGMENT}

We thank our donors and supporters in the process of carrying out this research.

We also thank our partners that support our rollout like Nahdlatul Ulama Ansor, Yayasan Cinta Anak Bangsa, Kampus Diakoneia Modern (Street Kids Foundation).

\section{REFERENCES}

[1] Olga Shabalina, Peter Mozelius, Pavel Vorobkalov."Creativity in digital pedagogy and game-based learning techniques; theoretical aspects, techniques and case studies", IEEE, Information, Intelligence, Systems and Applications (IISA), $20156^{\text {th }}$ International Conference

[2] Kirriemuir, J., \& McFarlane, A. (2004). Literature review in games and learning. Futurelab Series.

[3] UNESCO, "New UN study estimates 263 million children and youth now out of school", 2016

[4] Van Eck, R., 2006, Digital game-based learning: It's not just the digital natives who are restless. EDUCAUSE review, 41(2), 16.

[5] Roger C. Schank, "What We Learn When We Learn by Doing", Institute for the Learning Sciences Northwestern University, Technical Report No. 60 (1995)

[6] Kaylene C. Williams, Caroline C. Williams., Research in Higher Education Journal, 2011

[7] Hayne W. Reese, "The Learning-by-Doing Principle", Behavioral Development Bulletin, West Virginia University, 2011

[8] Jocelyn Shieh, "Analytics in the Gaming Industry: A Big Data Utopia", University of California Berkeley, 25 March 2016

[9] Andrew Popp, "Big data analytics adds new market plays for the video game industry", IBM Analytics, 27 January 2016 